\title{
Discovery and SAR of Thiazolidine-2,4-dione Analogues as Insulin-like Growth Factor-1 Receptor (IGF-1R) Inhibitors via Hierarchical Virtual Screening
}

\author{
Xiaofeng Liu ${ }^{\dagger}, *$ Hua Xie, ${ }^{*}{ }^{\S}$ Cheng Luo, ${ }^{\dagger}$ Linjiang Tong, ${ }^{\S}$ Yi Wang, ${ }^{\S}$ Ting Peng, ${ }^{\S}$ Jian Ding,${ }^{\S}$ Hualiang Jiang,,${ }^{\dagger}$ and \\ Honglin $\mathrm{Li}^{*}, *$ \\ ${ }^{\dagger}$ Drug Discovery and Design Center, Shanghai Institute of Materia Medica, Chinese Academy of Sciences, Shanghai 201203, China, \\ *Shanghai Key Laboratory of Chemical Biology, School of Pharmacy, East China University of Science and Technology, Shanghai 200237, China, \\ and ${ }^{\S}$ Division of Anti-Tumor Pharmacology, State Key Laboratory of Drug Research, Shanghai Institute of Materia Medica, \\ Chinese Academy of Sciences, Shanghai, 201203, China
}

Received December 3, 2009

Insulin-like growth factor-1 receptor (IGF-1R) is a growth factor receptor tyrosine kinase acting as a critical mediator of cell proliferation and survival. Novel 5-benzylidenethiazolidine-2,4-dione (5) and 5-(furan-2-ylmethylene)thiazolidine-2,4-dione (6) compounds were identified as potent and selective IGF-1 R inhibitors via hierarchical virtual screening. Initial SAR and biological activity of the analogues of $\mathbf{5}$ and $\mathbf{6}$ with thiazolidine-2,4-dione template are presented, and several inhibitors with low nanomolar potency are reported.

\section{Introduction}

The insulin-like growth factor-1 receptor $\left(\mathrm{IGF}-1 \mathrm{R}^{a}\right)$ is a member of the receptor tyrosine kinase family and plays a pivotal role in signaling pathway involving cell growth, proliferation, and apoptosis. ${ }^{1}$ Although highly related to insulin receptor (IR), it plays a different role in organism development, being responsible for normal growth and development as opposed to glucose homeostasis. ${ }^{2}$ Epidemiological studies indicate that the IGF-1 receptor is overexpressed in human cancers and primarily responsible for tumorigenesis, thereby increasing the risk of developing colon, breast, prostate, and lung tumors. ${ }^{3}$ Signaling through IGF-1R includes the activation of PI3K and Raf pathways. ${ }^{4}$ Inhibition of both of these pathways makes IGF-1R kinase a promising target for cancer therapy.

A variety of approaches have been or are currently being employed to suppress the activity of IGF-1R, which include monoclonal antibodies to the extracellular domain of the receptor, dominant-negative receptor proteins, antisense RNA, siRNA, and small-molecule inhibitors. ${ }^{5}$ Tremendous efforts have been made toward finding small molecules as IGF-1R ATP-competitive inhibitors. The selected structures of four potent inhibitors of IGF-1R kinase at discovery or preclinical stage are presented in Figure S1, which include benzimidazoles (1, BMS), ${ }^{6}$ isoquinolinediones $\left(\mathbf{2}\right.$, Wyeth) ${ }^{7} 3$ cyanoquinolines (3, Wyeth), ${ }^{8}$ and pyrazolopyrimidines (4, Abbott). ${ }^{9}$ Several cocrystal structures of IGF-1R with the

*To whom correspondence should be addressed. For H.X.: phone, +86-21-50806600-2422; fax, +86-21-50806722; e-mail, hxie@jding.dhs. org. For H.L.: phone, +86-21-64250213; fax, +86-21-64250213; e-mail, hlli@ecust.edu.cn.

${ }^{a}$ Abbreviations: IGF-1R, insulin-like growth factor-1 receptor; IR, insulin receptor; TZDs, thiazolidinediones; PPAR $\gamma$, peroxisome proliferator-activated receptor- $\gamma$; DS2.1, Discovery Studio 2.1; XP, extraprecision; VDW, van der Waals; SAR, structure-activity relationship; IFD, induced fit docking. inhibitors mentioned above have been determined and the ATP-binding site is confirmed as the inhibitors' binding site, which provides us crucial structural information for screening and design of novel IGF-1R inhibitors.

Thiazolidine-2,4-dione or thiazolidinediones (TZDs) recently emerged as potent antidiabetic agents targeting nuclear receptor, peroxisome proliferator-activated receptor- $\gamma$ $(\operatorname{PPAR} \gamma)$, and several TZDs have been approved by FDA for treating type 2 diabetes. ${ }^{10}$ Most recently, several TZD derivates have been reported as potent inhibitors of PI3K $\gamma,{ }^{11}$ Pim kinase family, ${ }^{12}$ and HIV-1 entry protein gp41, ${ }^{13}$ highlighting their versatile roles in multiple indications spanning from inflammatory diseases to cancers. However, to our knowledge, there are no public reports that identified TZDs as bearing potent inhibitory activity against IGF-1R except that some in vivo assays uncovered TZDs were involved in the process of IGF-1R pathway suppression. ${ }^{14}$ Taking advantage of complementing pharmacophore-based screening and docking-based screening techniques and overcoming their limitations, we searched the vendor database of SPECS via a hierarchical virtual screening strategy (see Figure 1 and Experimental Section) and identified 5-benzylidenethiazolidine-2,4-dione (5) and 5-(furan-2-ylmethylene)thiazolidine2,4-dione (6) compounds as inhibitors of IGF-1R kinase domain with promising potency (in vitro $\mathrm{IC}_{50}$ of 11.1 and $1.7 \mu \mathrm{M}$, respectively). Further results of initial SAR and bioactivity assay of the analogues of $\mathbf{5}$ and $\mathbf{6}$ with thiazolidine-2,4-dione template are also presented, and several inhibitors with low nanomolar potency are reported.

\section{Experimental Section}

The details of experiments on hierarchical virtual screening, HPLC analysis of the compounds' purification, enzymatic inhibitory assays, and $\mathrm{MCF}-7$ tumor cell line antiproliferative assay are presented in the Supporting Information. HPLC analysis of the compounds assayed confirmed the purity to be $>95 \%$.

Published on Web 02/23/2010 pubs.acs.org/jmc 


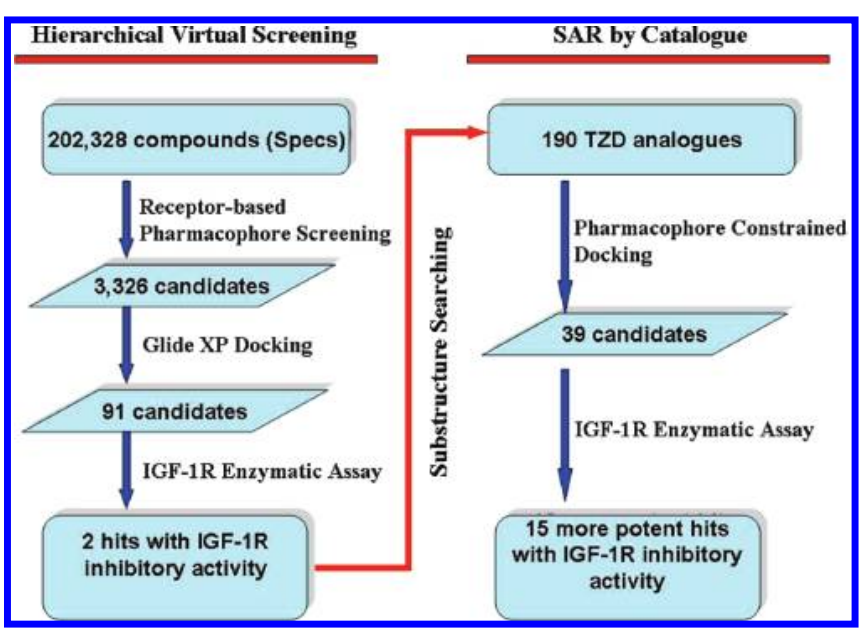

Figure 1. Schematic representation of the hits discovery strategy adopted.

\section{Results and Discussion}

The schematic representation of the hits discovery strategy adopted in this research is presented in Figure 1. Starting from the cocrystal structures IGF-1 R with pyridine-2-one inhibitor (PDB code 2OJ9), the crucial interaction information between the ligand and protein at the ATP-binding site was extracted and characterized with a pharmacophore model. Since many structural biology studies have confirmed that most known inhibitors can form one to three hydrogen bonds with the backbone in the "hinge" area, two hydrogen bond donor features targeting the backbone carbonyls of E1050 and M1052, one hydrogen bond acceptor targeting the backbone amide of M1052, and one more hydrophobic feature were characterized as the pharmacophore model in this study (Figure S2). However, in this study, the three HB constraints do not have to be completely fulfilled to find more structurally diverse potential "hits", which may form favored interactions with other parts of the binding site for the sake of inhibitory selectivity among different members of kinase family. This model was used to perform a pharmacophore-based searching to enrich the "hits" from the "large compounds pool". Then the top ranked "hits" from the pharmacophore filter were docked to the ATP-binding site by means of receptor based docking protocol. This hierarchical strategy efficiently reduced the number of "nonhits" passed to docking stage and consequently reduced the computational cost.

According to the binding affinities predicted in docking stage and manual inspection, 91 vendor-available compounds were purchased from SPECS for IGF-1R inhibitory activity assessment. The two most potent screening hits (5 and $\mathbf{6})$ are presented in Table 1 with in vitro $\mathrm{IC}_{50}<15.0 \mu \mathrm{M}$, both of which are structurally TZDs (5-benzylidenethiazolidine-2,4dione and 5-(furan-2-ylmethylene)thiazolidine-2,4-dione), uncovering the potential of adding the TZD derivatives to the portfolio of IGF-1R inhibitors.

To understand the structural basis for the binding of 5 and 6 to IGF-1R's ATP-binding site, we scrutinized the binding poses by means of molecular docking. Figure 2 shows the predicted binding poses of $\mathbf{5}$ and $\mathbf{6}$ in the ATP-binding site. The TZD moiety donates two hydrogen bonds via the NH group and the carbonyl oxygen to the hinge area as predicted in the pharmacophore model. The benzene ring and the furan ring make numerous VDW contacts with the hydrophobic cleft formed by V983 and M1126. The predicted binding poses suggest the binding affinities of $\mathbf{5}$ and $\mathbf{6}$ can be further optimized by varying the substituents on the benzene rings to a larger scope.

After the initial hits were identified, a "SAR by catalog" analysis was performed. With unsubstituted 5-benzylidenethiazolidine-2,4-dione and 5-(furan-2-ylmethylene)thiazolidine-2,4-dione as query scaffold, a focused library containing 190 TZD motifs of $\mathbf{5}$ and $\mathbf{6}$ are extracted from the SPECS database by substructure search. According to isosteric replacement theory, the carbonyl oxygen on the TZD ring is allowed to hop to sulfur or nitrogen. To inspect the impact on the activities imposed by the geometric isomerism of the double bond, the query double bond incorporated $Z$ and $E$ isomers. The focused library was docked to the binding site with our inhouse pharmacophore-constrained docking protocol PACDock and ranked by KScore (see Figure 1 and Supporting Information). After visual inspection, 39 compounds were purchased from the vendor and their inhibitory activities against IGF-1R were assessed. The results are summarized in Table 1.

The data demonstrate that 15 new compounds are in various degrees more potent than the original screening hits, with $\mathrm{IC}_{50}$ for derivates of 5 of $2.1-10.2 \mu \mathrm{M}$ and for derivates of 6 of $0.057-0.4 \mu \mathrm{M}$. As for derivates of 5, smaller substitutents at the ortho position of benzilidines such as halogens and hydroxyl basically retain or decrease the activity slightly (7a and 15a); however, the activities decrease significantly or completely vanished in the case of bulky substitutes, e.g., 8a. This can be interpreted with the predicted docking model in Figure 2: the hydroxyl at the ortho position may form a hydrogen bond with the side chain of K1003. Given that a relatively weaker hydrogen bond acceptor as the fluorine atom is, the activity of $\mathbf{7 a}$ is basically comparable with those of 5 and 15a. Because of the limited size of the region near K1003, bulky substituents at this position are not tolerated. Accordingly, the activity is not very sensitive to the sizes or physiochemical properties of the substitutes at the meta position (10a vs 11a). Nevertheless the substituents at the para position are extremely size-constrained and any bulky para substituents substantially decrease the potency (13a vs 12a and 14a). For 2,3-bisubstituted analogues of 5, the activities are affected significantly by the substituents with different steric volumes; for example, switching the flexible isobutoxy and methyl acetate to more rigid and steric hindered benzyloxy groups nearly deactivated the compounds completely (22a and 23a vs 19a and 20a). Similarly, multiple adjacent bulky groups for 2,3,4-trisubstituents combinations are undesired because of poor inhibitory results, and smaller hydrogen bond acceptor groups like hydroxyl or methoxyl contribute to better activity (e.g., 28a, 30a, 32a, and 33a vs 31a and 34a). The molecular docking result of 22a (Figure S3) indicates that the hydrophobic pocket near I1130 is very size-constrained and can only be occupied by small substituents or flexible hydrophobic chain as the isobutoxy on 22a, while the bulky and rigid benzyloxy cannot occupy this size-limited pocket and render the inactivity of 19a and 20 a accordingly.

For derivates of $\mathbf{6}$, halogen substituents at the ortho position of benzene ring decrease the potency by 10 -fold (35b); however, it is noteworthy that $m$-bromine promotes the potency significantly by nearly 30 -fold (36b). The significant gain of binding affinity may attribute to a newly reported type of $\mathrm{X}-\mathrm{O}$ interaction widely existing in the protein-ligand crystal complexes. ${ }^{15}$ At the same time, the activities of analogues of $\mathbf{6}$ are remarkably affected by physiochemical 
Table 1. In Vitro SAR of Thiazolidinediones

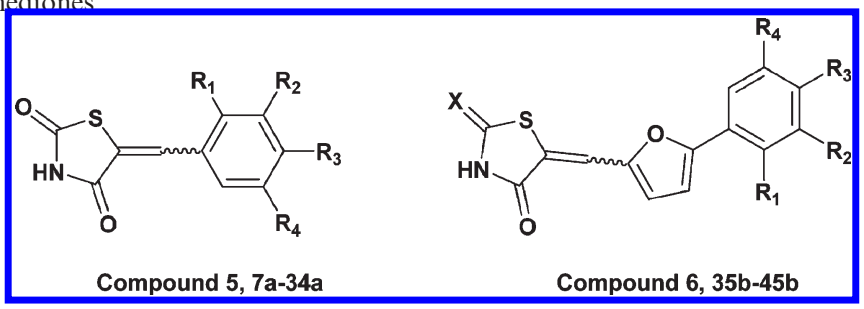

\begin{tabular}{|c|c|c|c|c|c|c|c|}
\hline Compd $^{\mathrm{a}}$ & $\mathrm{R}_{1}$ & $\mathrm{R}_{2}$ & $\mathrm{R}_{3}$ & $\mathrm{R}_{4}$ & IGF-1R ${ }^{b}$ & $\mathrm{IR}^{\mathrm{c}}$ & $\mathrm{MCF}-7^{\mathrm{d}}$ \\
\hline $5(Z)$ & $\mathrm{OH}$ & $\mathrm{OMe}$ & $\mathrm{H}$ & $\mathrm{Br}$ & 11.1 & $>100.0$ & ND \\
\hline $6(Z)$ & $\mathrm{NO}_{2}$ & $\mathrm{H}$ & $\mathrm{H}$ & $\mathrm{H}$ & 1.71 & $36.3 \pm 2.5$ & $\mathrm{ND}$ \\
\hline $7 \mathbf{a}(Z)$ & $\mathrm{F}$ & $\mathrm{H}$ & $\mathrm{H}$ & $\mathrm{H}$ & $6.6 \pm 1.7$ & $>100.0$ & $>100.0$ \\
\hline $8 \mathbf{a}(E)$ & $*$ & $\mathrm{H}$ & $\mathrm{H}$ & $\mathrm{H}$ & $>100.0$ & ND & ND \\
\hline 9a $(E)$ & .0 & $\mathrm{H}$ & $\mathrm{H}$ & $\mathrm{H}$ & $9.0 \pm 1.7$ & $>100.0$ & $>100.0$ \\
\hline $10 \mathrm{a}(Z)$ & $\mathrm{H}$ & & $\mathrm{H}$ & $\mathrm{H}$ & $1.6 \pm 0.6$ & $>100.0$ & $25.2 \pm 2.0$ \\
\hline $11 \mathbf{a}(E)$ & $\mathrm{H}$ & $\mathrm{NO}_{2}$ & $\mathrm{H}$ & $\mathrm{H}$ & $4.9 \pm 0.7$ & $>100.0$ & $55.8 \pm 3.8$ \\
\hline $12 \mathbf{a}(E)$ & $\mathrm{H}$ & $\mathrm{H}$ & & $\mathrm{H}$ & $>100.0$ & ND & ND \\
\hline $13 \mathbf{a}(Z)$ & $\mathrm{H}$ & $\mathrm{H}$ & Et & $\mathrm{H}$ & $11.1 \pm 4.0$ & $>100.0$ & $>100.0$ \\
\hline $14 \mathrm{a}(Z)$ & $\mathrm{H}$ & $\mathrm{H}$ & $\mathrm{O}-{ }^{n}$ butyl & $\mathrm{H}$ & $>100.0$ & ND & ND \\
\hline $15 \mathbf{a}(E)$ & $\mathrm{OH}$ & $\mathrm{OEt}$ & $\mathrm{H}$ & $\mathrm{H}$ & $8.6 \pm 0.6$ & $>100.0$ & $>100.0$ \\
\hline $16 \mathbf{a}(Z)$ & $\mathrm{Cl}$ & $\mathrm{H}$ & $\mathrm{Cl}$ & $\mathrm{H}$ & $15.0 \pm 7.2$ & $>100.0$ & $>100.0$ \\
\hline $17 \mathbf{a}(E)$ & $\mathrm{H}$ & $\mathrm{Cl}$ & $\mathrm{Cl}$ & $\mathrm{H}$ & $8.8 \pm 4.7$ & $>100.0$ & $50.8 \pm 6.6$ \\
\hline $18 \mathbf{a}(E)$ & $\mathrm{H}$ & $\mathrm{OMe}$ & OEt & $\mathrm{H}$ & $16.8 \pm 11.0$ & $>100.0$ & $87.3 \pm 1.6$ \\
\hline $19 \mathfrak{a}(Z)$ & $\mathrm{H}$ & $\mathrm{OMe}$ & & $\mathrm{H}$ & $>100.0$ & ND & ND \\
\hline $\mathbf{2 0 a}(E)$ & $\mathrm{H}$ & $\mathrm{OMe}$ & O-benzyl & $\mathrm{H}$ & $>100.0$ & ND & $\mathrm{ND}$ \\
\hline 21a $(E)$ & $\mathrm{H}$ & $\mathrm{F}$ & $+N D$ & $\mathrm{H}$ & $>100.0$ & $\mathrm{ND}$ & $\mathrm{ND}$ \\
\hline $22 \mathbf{a}(Z)$ & $\mathrm{H}$ & OEt & O-butyl & $\mathrm{H}$ & $63.9 \pm 6.1$ & $\mathrm{ND}$ & ND \\
\hline 23a $(E)$ & $\mathrm{H}$ & $\mathrm{OEt}$ & " & $\mathrm{H}$ & $28.0 \pm 12.2$ & $\mathrm{ND}$ & ND \\
\hline $24 \mathbf{a}(Z)$ & OEt & $\mathrm{H}$ & \multicolumn{2}{|c|}{$[1,3]$ dioxole } & $10.0 \pm 7.9$ & $>100.0$ & $>100.0$ \\
\hline 25a $(E)$ & $\mathrm{Br}$ & $\mathrm{H}$ & \multicolumn{2}{|c|}{$[1,3]$ dioxole } & $3.3 \pm 1.6$ & $>100.0$ & $24.8 \pm 11.7$ \\
\hline $26 \mathbf{a}(Z)$ & $\mathrm{Br}$ & II & $\mathrm{OMe}$ & OEt & $>100.0$ & ND & ND \\
\hline $27 \mathbf{a}(Z)$ & $\mathrm{OH}$ & OEt & $\mathrm{H}$ & $\mathrm{Br}$ & $3.3 \pm 1.7$ & $>100.0$ & ND \\
\hline 28a $(Z)$ & $\mathrm{H}$ & $\mathrm{Br}$ & $\mathrm{OMe}$ & $\mathrm{Br}$ & $6.4 \pm 3.7$ & $65.3 \pm 11.1$ & $\mathrm{ND}$ \\
\hline $29 \mathbf{a}(E)$ & $\mathrm{H}$ & $\mathrm{Cl}$ & OEt & OEt & $49.8 \pm 18.7$ & $\mathrm{ND}$ & ND \\
\hline $30 \mathbf{a}(E)$ & $\mathrm{H}$ & OEt & $\mathrm{OH}$ & $\mathrm{Br}$ & $5.2 \pm 0.4$ & $>100.0$ & $56.3 \pm 22.9$ \\
\hline 31a $(Z)$ & $\mathrm{H}$ & OEt & O- ${ }^{n}$ propyl & $\mathrm{Br}$ & $>100.0$ & ND & ND \\
\hline 32a $(E)$ & $\mathrm{H}$ & $\mathrm{OMe}$ & $\mathrm{OH}$ & OMe & $5.3 \pm 2.8$ & $>100.0$ & ND \\
\hline 33a $(E)$ & $\mathrm{H}$ & $\mathrm{OMe}$ & $\mathrm{OH}$ & I & $6.3 \pm 0.5$ & $>100.0$ & $50.8 \pm 15.8$ \\
\hline 34a $(Z)$ & $\mathrm{H}$ & $\mathrm{OMe}$ & $\mathrm{OMe}$ & * ح & $>100.0$ & ND & ND \\
\hline
\end{tabular}


Table 1. Continued

\begin{tabular}{|c|c|c|c|c|c|c|c|}
\hline Compd $^{\mathrm{a}}$ & $\mathrm{R}_{1}$ & $\mathrm{R}_{2}$ & $\mathrm{R}_{3}$ & $\mathrm{R}_{4}$ & IGF-1R & $\mathrm{IR}^{\mathrm{c}}$ & $\mathrm{MCF}-7^{\mathrm{d}}$ \\
\hline 35b $(Z)^{*}$ & $\mathrm{Cl}$ & $\mathrm{H}$ & $\mathrm{H}$ & $\mathrm{H}$ & $8.2 \pm 11.1$ & $79.5 \pm 3.7$ & $>100.0$ \\
\hline 36b $(E)$ & $\mathrm{H}$ & $\mathrm{Br}$ & $\mathrm{H}$ & $\mathrm{H}$ & $\begin{array}{ll}0.057 \quad \pm \\
0.01\end{array}$ & $28.0 \pm 12.3$ & $25.3 \pm 3.2$ \\
\hline $\mathbf{3 7 b}(Z)^{*}$ & $\mathrm{H}$ & $\mathrm{H}$ & $\mathrm{COOH}$ & $\mathrm{H}$ & $\begin{array}{l}0.061 \pm 0.02 \\
7\end{array}$ & $19.5 \pm 3.2$ & $41.9 \pm 14.9$ \\
\hline $\mathbf{3 8 b}(E)$ & $\mathrm{H}$ & $\mathrm{H}$ & $\mathrm{Br}$ & $\mathrm{H}$ & $6.7 \pm 1.8$ & $>100.0$ & $47.3 \pm 25.7$ \\
\hline $39 \mathbf{b}(E)$ & $\mathrm{H}$ & $\mathrm{H}$ & $\mathrm{F}$ & $\mathrm{H}$ & $0.4 \pm 0.4$ & $>100.0$ & $36.9 \pm 2.6$ \\
\hline $40 \mathrm{~b}(E)$ & $\mathrm{Cl}$ & $\mathrm{Cl}$ & $\mathrm{H}$ & $\mathrm{H}$ & $3.4 \pm 3.7$ & $>100.0$ & $21.5 \pm 11.2$ \\
\hline $41 b(E)$ & $\mathrm{Cl}$ & $\mathrm{H}$ & $\mathrm{Cl}$ & $\mathrm{H}$ & $1.6 \pm 1.2$ & $27.3 \pm 4.1$ & $17.3 \pm 5.9$ \\
\hline $42 \mathrm{~b}(E)$ & $\mathrm{Br}$ & $\mathrm{H}$ & $\mathrm{Me}$ & $\mathrm{H}$ & $6.3 \pm 3.9$ & $>100.0$ & ND \\
\hline $43 \mathrm{~b}(E)$ & $\mathrm{H}$ & $\mathrm{Cl}$ & $\mathrm{F}$ & $\mathrm{H}$ & $0.28 \pm 0.03$ & $>100.0$ & $16.9 \pm 8.0$ \\
\hline $44 \mathrm{~b}(E)$ & $\mathrm{H}$ & $\mathrm{Cl}$ & $\mathrm{Cl}$ & $\mathrm{H}$ & $2.9 \pm 3.1$ & $57.6 \pm 6.0$ & $14.8 \pm 4.4$ \\
\hline $45 b(Z)$ & $\mathrm{H}$ & $\mathrm{COOH}$ & $\mathrm{OH}$ & $\mathrm{H}$ & $0.25 \pm 0.21$ & $0.905 \pm 0.021$ & $81.3 \pm 25.9$ \\
\hline
\end{tabular}

${ }^{a}$ The geometrical isomerism of the double bond is labeled in parentheses. ${ }^{b} \mathrm{IC}_{50}$ average values and corresponding $\mathrm{SD}$ values (in $\mu \mathrm{M}$ ) are determined from the results of at least three independent tests of IGF-1R tyrosine kinase. ${ }^{c} \mathrm{IC}_{50}$ average values and corresponding $\mathrm{SD}$ values (in $\mu \mathrm{M}$ ) are determined from the results of at least three independent tests of IR inhibition assay. ${ }^{d} \mathrm{IC}_{50}$ average values and corresponding SD values (in $\mu \mathrm{M}$ ) are determined from the results of at least three independent tests of MCF-7 cell line antiproliferative assay. ${ }^{e}(*) \mathrm{X}=\mathrm{S}$. ND, not determined.

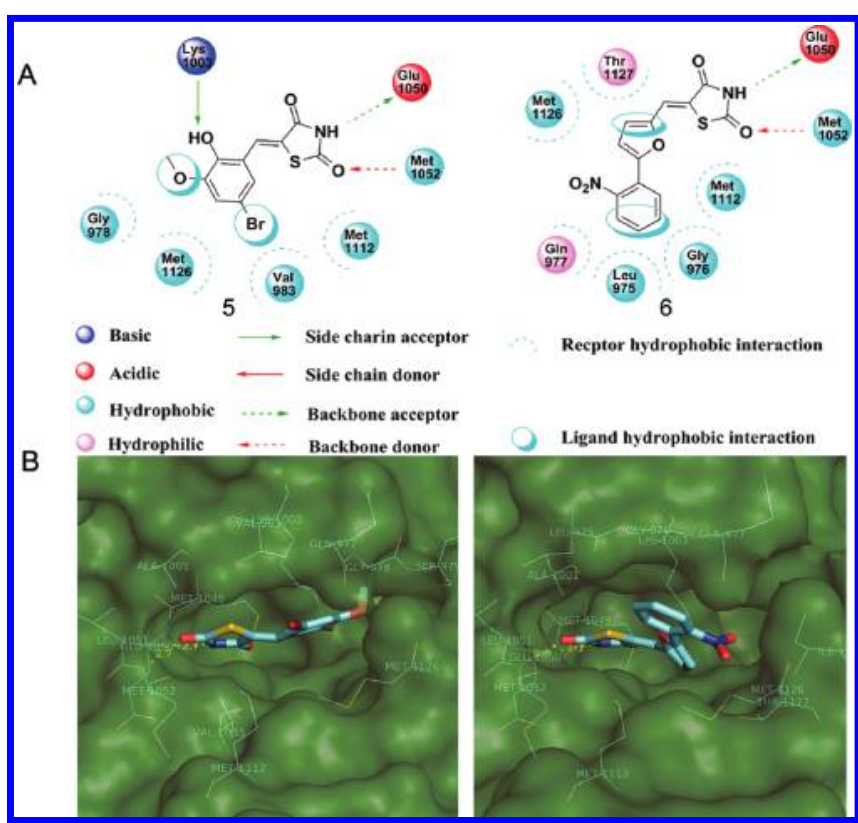

Figure 2. Two-dimensional (2A) and three-dimensional (2B) interaction schemes of docked poses of 5 and 6 in IGF-1R receptor structure. The ligands are shown as sticks and the non-carbon atoms are colored by atom types with hydrogen atoms omitted for clarity. Critical residues of the binding pocket are shown as lines in cyan. Hydrogen bonds are shown as dotted yellow lines with distance between donor and acceptor atoms.

properties of the substitutes at the para position of the benzene ring: polar groups such as carboxylate and hydroxyl are desirable and consequently increase the activity by 30 - and 7-fold, respectively. However, the hydrophobic substituents are unfavored and the respective potency decreased significantly in cases of fluorine, bromine, and methyl, according to their correspondingly increasing hydrophobicity (37b and $\mathbf{4 5 b}$ vs 38b, 39b, and 42b). The receptor model we used (2OJ9) for initial docking is the inactive conformation of IGF-1R, according to the binding pose predicted for $\mathbf{6}$ in Figure 2. The significant gain of binding affinity is hard to interpret because the para- and meta-carboxylates are largely solvent exposed in such cases (data not shown), which indicates that different binding poses for $\mathbf{3 7 b}$ and $\mathbf{4 5} \mathbf{b}$ may exist. Such hypothesis is partly validated by flexible receptor docking, indicating that a potential salt bridge may be formed between the para-carboxylate and K1003 (Figures S4 and S5).

Moreover, it seems that both activities of derivates of $\mathbf{5}$ and $\mathbf{6}$ are not notably affected by the double bond isomerism, probably attributed to the quasi-symmetric topological distribution of the elements of hydrogen bonds on the TZD moiety, which is believed to be pivotal to anchor the binding pose in IGF-1R site. That can be partially supported by the fact that $Z$ and $E$ isomers with similar substituents retain inhibitory potency for IGF-1R (19a vs 20a and 22a vs 23a).

Since IGF-1R is highly homological to IR in sequence and structure but with completely different biological function roles, the selectivity against IGF-1R over IR has to be taken into consideration at the very beginning of IGF-1 R inhibitory lead compounds discovery and design. Table 1 also summarizes selectivity versus IR for selected derivates. At this point, we achieved an apparent window of selectivity, as most compounds are almost completely inactive against IR and the most potent compounds (36b and 37b) achieve 491- and 319fold selectivity for IGF-1R over IR, respectively. Even for the worst case, the selectivity ratio ( $\mathrm{IR} / \mathrm{IGF}-1 \mathrm{R}$ in $\mathrm{IC}_{50}$ ) amounts to 3.62. We have also performed the kinase selectivity profiling assay with hit $\mathbf{5}$ against a small panel of tyrosine and serine/threonine kinases (Figure S6), and it presents good selectivity against IGF-1R over most kinases except c-Src. The 
overall results are promising in that our compound may bear excellent inhibitory preference for IGF-1R.

We selected 23 of the 39 derivatives described herein with in vitro $\mathrm{IC}_{50}$ lower than $10 \mu \mathrm{M}$ for the assessment of antiproliferative potencies on IGF-1 mediated cell growth of MCF-7 human breast cancer cell line (Table 1). The most potent compound in suppressing the proliferation of MCF-7 cell was 44b with an antiproliferative $\mathrm{IC}_{50}$ of $14.8 \mu \mathrm{M}$. Since cell antiproliferative potency reflects the compounds' binding affinities to the target protein and their ability to enter the cell, the slight acidity of the thiazolidine-2,4-dione group $\left(\mathrm{p} K_{\mathrm{a}} \approx 7.9\right)$ may hamper cell penetration. This is similar to the recent finding of Smith et al., ${ }^{12}$ who have observed similar poor cell antiproliferative activity for their TZD-based Pim kinase inhibitor. Further research involving cocrystal structures resolution, structural modification, and in vivo antiproliferative activities against other tumor models are under progress.

\section{Conclusions}

We discovered two potent IGF-1R kinase inhibitors via hierarchical strategy based virtual screening. Our effort led to a novel series of IGF-1R inhibitors with 5-benzylidenethiazolidine-2,4-dione and 5-(furan-2-ylmethylene) thiazolidine2,4-dione scaffolds, which demonstrate excellent inhibitory potency and selectivity against IGF-1R over IR. Subsequent structural optimization and SAR analysis led to the discovery of the most potent analogues with in vitro $\mathrm{IC}_{50}$ amounting to 57 and $61 \mathrm{nM}$, respectively. This effort will form the basis for further modification of the structure of the hits discovered in this work and validation of corresponding in vivo activities. The new high selective IGF-1 R inhibitors can be developed into new antitumor agents and potential molecular probes to differentiate the biological roles played by IGF-1R and IR.

Acknowledgment. This work was supported by the National Natural Science Foundation of China (Grants 20803022, 30672539, and 20721003), the 863 Hi-Tech Program of China (Grant 2007AA02Z304), the Special Fund for Major State Basic Research Project (Grant 2009CB918500), the Shanghai Committee of Science and Technology (Grants 09dZ1975700 and 08JC1407800), and the National S\&T Major Project, China (Grants 009ZX09501-001, 2009ZX09301-001, and 2009ZX09103-102). H.L. is also sponsored by Shanghai Rising-Star Program (Grant 10QA1401800). We also thank Prof. Yufang Xu and Dr. Ye Zhong for their helpful discussions and suggestions.

Supporting Information Available: The details of experiments on database preparation, hierarchical virtual screening, HPLC analysis of the compounds' purification, enzymatic inhibitory assays, and MCF-7 tumor cell line antiproliferative assay; HPLC analysis data of the 39 hits; visualization of the binding pose of 22a and the pharmacophore model extracted from crystal structure of $2 \mathrm{OJ} 9$; binding poses of $\mathbf{3 7 b}$ predicted by induced fit docking in 2ZM3 (active conformation) and 2OJ9 (inactive conformation); inhibitory profiling result of $\mathbf{5}$ against
15 kinases; results of pharmacophore model for $2 \mathrm{OJ} 9$ as an Accelrys CHM listing. This material is available free of charge via the Internet at http://pubs.acs.org.

\section{References}

(1) Randhawa, R.; Cohen, P. The role of the insulin-like growth factor system in prenatal growth. Mol. Genet. Metab. 2005, 86, 84-90.

(2) Blakesley, V. A.; Scrimgeour, A.; Esposito, D.; Le Roith, D. Signaling via the insulin-like growth factor-I receptor: Does it differ from insulin receptor signaling? Cvtokine Growth Factor Rev. 1996, 7, 153-159.

(3) Khandwala, H. M.; McCutcheon, I. E.; Flyvbjerg, A.; Friend, K. E. The effects of insulin-like growth factors on tumorigenesis and neoplastic growth. Endocr. Rev. 2000, 21, 215-244.

(4) Baserga, R.; Peruzzi, F.; Reiss, K. The IGF-1 receptor in cancer biology. Int. J. Cancer 2003, 107, 873-877.

(5) Bohula, E. A.; Playford, M. P.; Macaulay, V. M. Targeting the type 1 insulin-like growth factor receptor as anti-cancer treatment. AntiCancer Drugs 2003, 14, 669-682.

(6) Wittman, M.; Carboni, J.; Attar, F.; Balasubramanian, B.; Balimane, P.; Brassil, P.; Beaulieu, F.; Chang, C.; Clarke, W.; Dell, J.; Eummer, J.; Frennesson, D.; Gottardis, M.; Greer, A.; Hansel, S.; Hurlburt, W.; Jacobson, B.; Krishnananthan, S.; Lee, F. Y.; Li, A.; Lin, T.-A.; Liu, P.; Ouellet, C.; Sang, X.; Saulnier, M. G.; Stoffan, K.; Sun, Y.; Velaparthi, U.; Vyas, D.; Wong, H.; Yang, Z.; Zimmermann, K.; Zoeckler, M.; Vyas, D. Discovery of a $(1 \mathrm{H}$ benzimidazol-2-yl)-1 $H$ - pyridine-2-one (BMS-536924) inhibitor of insulin-like growth factor I receptor kinase with in vivo antitumor activity. J. Med. Chem. 2005, 48, 5639-5643.

(7) Mayer, S. C.; Banker, A. L.; Boschelli, F.; Di, L.; Johnson, M.; Kenny, C. H.; Krishnamurthy, G.; Kutterer, K.; Moy, F.; Petusky, S.; Ravi, M.; Tkach, D.; Tsou, H. R.; Xu, W. Lead identification to generate isoquinolinedione inhibitors of insulin-like growth factor receptor (IGF-1R) for potential use in cancer treatment. Bioorg. Med. Chem. Lett. 2008, 18, 3641-3645.

(8) Miller, L. M.; Mayer, S. C.; Berger, D. M.; Boschelli, D. H.; Boschelli, F.; Di, L.; Du, X.; Dutia, M.; Floyd, M. B.; Johnson, M.; Kenny, C. H.; Krishnamurthy, G.; Moy, F.; Petusky, S.; Tkach, D.; Torres, N.; Wu, B.; Xu, W. Lead identification to generate 3-cyanoquinoline inhibitors of insulin-like growth factor receptor (IGF-1R) for potential use in cancer treatment. Bioorg. Med. Chem. Lett. 2009, 19, 62-66.

(9) Hubbard, R. D.; Bamaung, N. Y.; Palazzo, F.; Zhang, Q.; Kovar, P.; Osterling, D. J.; Hu, X.; Julie; Wilsbascher, J. L.; Johnson, E. F.; Bouska, K.; Wang, J.; Bell, R. L.; Davidsen, S. K.; Sheppard, G. S. Pyrazolo[3,4- $d]$ pyrimidines as potent inhibitors of the insulin-like growth factor receptor (IGF-1R). Bioorg. Med. Chem. Lett. 2007, 17, 5406-5409.

(10) Heidi, S. C. Thiazolidinediones in diabetes: current status and future outlook. Curr. Opin. Invest. Drugs 2003, 4, 406-411.

(11) Camps, M.; Rückle, T.; Ji, H.; Ardissone, V.; Rintelen, F.; Shaw, J.; Ferrandi, C.; Chabert, C.; Gillieron, C.; Françon, B.; Martin, T.; Gretener, D.; Perrin, D.; Leroy, D.; Vitte, P. A.; Hirsch, E.; Wymann, M. P.; Cirillo, R.; Schwarz, M. K.; Rommel, C. Blockade of PI3Kgamma suppresses joint inflammation and damage in mouse models of rheumatoid arthritis. Nat. Med. 2005, 11, 936-943.

(12) Xia, Z.; Knaak, C.; Ma, J.; Beharry, Z. M.; Mclnnes, C.; Wang, W.; Kraft, A. S.; Smith, C. D. Synthesis and evaluation of novel inhibitors of Pim-1 and Pim-2 protein kinases. J. Med. Chem. 2005, 9, 74-86.

(13) Katritzky, A. R.; Tala, S. R.; Lu, H.; Vakulenko, A. V.; Chen, Q. Y.; Sivapackiam, J.; Pandya, K.; Jiang, S.; Debnath, A. K. Design, synthesis, and structure-activity relationship of a novel series of 2-aryl 5-(4-oxo-3-phenethyl-2-thioxothiazolidinylidenemethyl)furans as HIV-1 entry inhibitors. J. Med. Chem. 2009, 52, 7631-7639.

(14) Guobin, H.; Youme, S.; John, D.; Susan, M. F. Thiazolidinediones inhibit insulin-like growth factor-I induced activation of p70S6 kinase and suppress insulin-like growth factor-I tumor-promoting activity. Cancer Res. 2006, 66, 1873-1879.

(15) Lu, Y.; Shi, T.; Wang, Y.; Yang, Y.; Yan, X.; Luo, X.; Jiang, H.; Zhu, W. Halogen bonding, a novel interaction for rational drug design? J. Med. Chem. 2009, 52, 2854-2862. 